\title{
Shear Stress Distribution in the Opening Chords of Hybrid R/C T- Beams with Opening
}

\author{
Jonie Tanijaya ${ }^{1}$ \\ ${ }^{1}$ Civil Engineering Department, Paulus Christian University of Indonesia
}

\begin{abstract}
This study is carried out to evaluate the potential of three hybrid T-beams with web openings theoretical shear stresses distribution. The shear stresses at the opening edges were plotted at the working stage, yielding stage and collapse stage for these three tested beams. The available experimental results from the previous research was compared to the finite element results as well as the developed analytical. The shear stress distribution at the middle of the top and bottom chords of the opening in pure bending region are zero. At the upper and lower corners of the opening occurs the maximum shear stresses. The maximum shear stress occurs at the right lower corner chord at the high moment edge and at the left upper corner chord at the low moment edge in beams with openings at high shear and high flexural - shear region. Furthermore, an extensive parametric study is performed on these beams to find the distributing ratio of the shear force between the opening chords. The shear force at an opening in hybrid R/C T-beam is carried by the top and bottom chords of the opening according to the area - moment of inertia root ratio with the correction factor 0.70 .
\end{abstract}

\section{Introduction}

Web opening in beams occur quite often in practice to provide convenient passage of environmental services to provide passage for utility duct and pipes, it also translates into substantial economic savings in the construction of a multi-storey building [1]. It has been practiced that pipes and ducts are usually hanged below the floor beams, and covered by a suspended ceiling for its aesthetic purpose. These openings can be of different shapes and sizes as circular, square or rectangular. As a results, story heights in buildings can be reduced resulting in major cost savings. Some openings generally give rise to excessive deflections and stresses which have to be taken into consideration. Utilization of high strength concrete in construction sector has increased due to its improved mechanical properties compared to ordinary concrete [2]. One such mechanical property, shear resistance of concrete beams is an intensive area of research. Providing an opening in beam develops cracks around the opening due to stress concentration [3]. Therefore, it is important to predict accurately the distribution of shear between the top and bottom chords of the opening. Beam openings may be of different shapes, sizes and are generally located close to the supports where shear is dominant. The behavior of such beams is affected by the size and location of the openings [4]. In practical life it is quite often use to provide convenient passage of environmental services which reduce the story heights of buildings and weight of concrete beams as it improves the demand on the supporting frame both under gravity loading and seismic excitation which results in major cost saving.

Openings should be positioned on the concrete beams to provide chords with sufficient concrete area for developing ultimate compression block in flexure and adequate depth for providing effective shear reinforcement [5]. The presence of openings will transform simple beam behaviour into a more complex behaviour, as we induce a sudden change in the dimension of the beam's cross section. The ultimate strength, crack width shear strength and stiffness may also be seriously affected [6]. Dinakaran and Sastry [7] suggested that the amount of the transverse shear distributed to each chord is depending on its respective cross-sectional areas. On the other hand, Barney et al. [8] proposed that the total shear force should be proportioned according to the moments of inertia of the chords for un-cracked section. Once a chord(s) has cracked, the distribution of shear will depend on the extent of cracking.

More recently, Kennedy and Abdalla [9] formulated a root ratio, dependent on the area and moment of inertia of each chord, for distributing the shear force between the top and bottom chords in beams with opening. The design for a beam with a large opening had been proposed that the top and bottom cross members of the opening could be assumed to behave like a vierendeel panel. The top and bottom chord members were expected to carry shear and axial force acted from the bending moment [10]. The openings should be provided so that chords have enough concrete area to develop the ultimate compression block in flexure and sufficient

\footnotetext{
* Corresponding author: jonie.tanijaya@gmail.com
} 
depth to provide efficient shear reinforcement. They should not be deeper than one-half the beam depth and should be located not closer than one-half the beam depth from supports or concentrated loads. In continuous beams that generally occur in practice, reduction in stiffness due to the provision of opening through webs causes a redistribution of internal forces and moment, the amount of which needs to be evaluated before a design can proceed. In some researches, generally the opening are applied on normal concrete beams with conventional aggregates. Light weight concrete application has enormous benefits in an effort to reduce the weight of structure, so theoritically it could minimize structure dimension which also means construction cost savings can be achieved. This research is using light weight concrete utilizing locally expanded clay aggregates applied on T-beams with web opening.

Finite element analysis is more superior to the conventional design approach in terms of robustness and applicability for such severe nonlinear structural behaviour [11]. Though, the development of a finite element model (FEM) may need intensive material testing to incorporate into the material model in any of the finite element (FE) packages available [12]. In the present paper, using the 'ABAQUS' computer program [13], theoretical analyses were carried out on three hybrid R/C T-beams with rectangular web opening. The opening was provided in the web of the beams, i.e. in the pure bending region, the high shear region, and the high flexural-shear region, respectively (Figure 1).

The finite element method was used to conduct an extensive parametric study on the static response of simply supported beam with rectangular opening. The shear stresses at the opening edges at the working stage, yielding stage and collapse stage were plotted for the three tested beams. A parametric study was undertaken to detemine the ratio of the shear force carried by each chord of the opening. The available experimental results from the previous research have been compared to the finite element results as well as with results obtained from the developed analytical approach. Good agreement was observed [14].

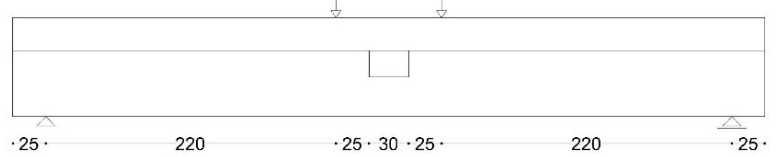

a. Opening in pure bending region BLT-1

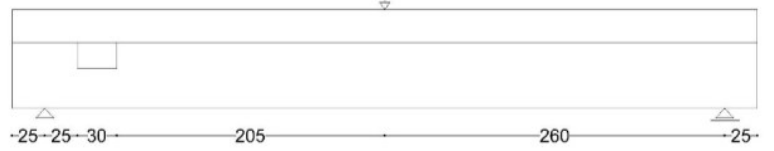

b. Opening in high shear region BLT-2

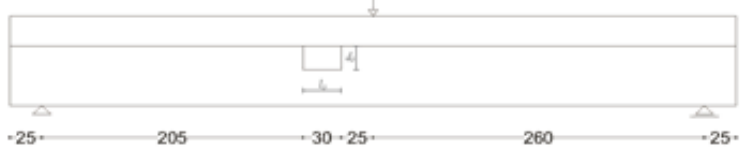

c. Opening in high flexural-shear region BLT-3

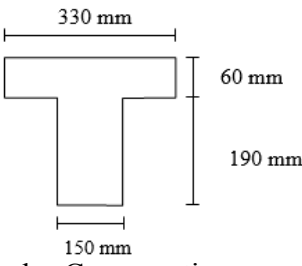

d. Cross section

Fig. 1. Beam identification

\section{Distribution of Shear Stress in the Vicinity of the Opening Chords}

Distribution of shear stresses in the vicinity of the opening chords from BLT-1. BLT-2, and BLT-3 with the difference loading are shown in Figure 2, 3 and 4. Figure 2(a) shows that the shear stress distribution at the middle of the top and bottom chords are zero at the working, yielding and collapse stages. This is due to the position of the beam opening (pure bending zone). From the Figure 2(b), it can be observed from these results that at collapsed stage (ultimate load) the maximum shear stress occurs at the opening corners with different stages. At the upper corner of the opening occurs positive shear stress and at the lower corner occurs negative shear stress. Figure 3(a) shows that prior to the beam collapse (close to the ultimate load) the maximum shear stress at middle of the top and bottom chords increase. It can be seen that the top chord carries only about $1 / 3$ of the bottom chords. Figure 3(b) and 3(c) show the maximum shear stress occur at the right lower corner chord at the high moment edge and at the left upper corner chord at the low moment edge.

Figure 4(a) shows shear stress distributions at the lower middle chord occurs different sign. Shear force at the lower chord decrease with the applied load increasing, this is caused reducing cross dimension of beam. After cracking (Figure 4 (b) and (c)), with the increasing load, the shear stress distributions at the edge of opening are similar to those for BLT-2, the maximum shear stress occur at the right lower corner chord at the high momen edge and at the left upper corner chord at the low moment edge. Shear force at the opening chords cause secondary moment at the vicinity opening, which can caused crack at the corners of the chord. 


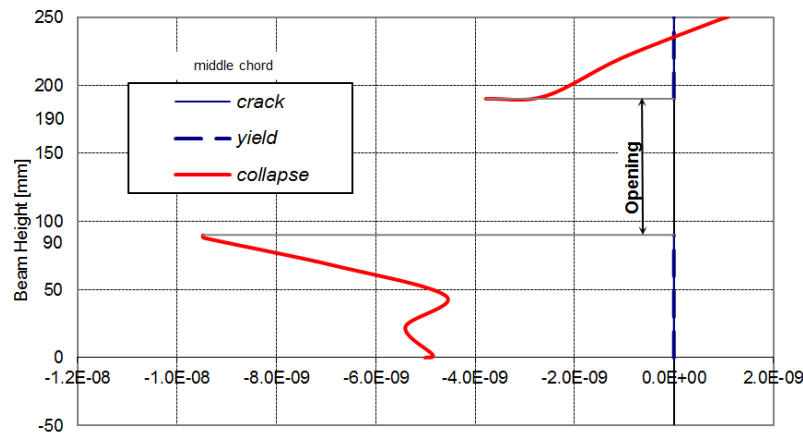

Shear stress [MPa]

a. Middle chords

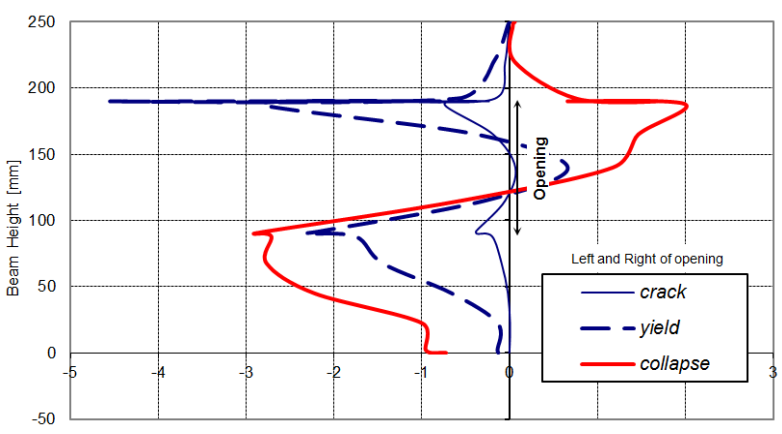

Shear Stress [MPa]

b. Opening edges

Fig. 2. Shear stress distribution fo BLT-1

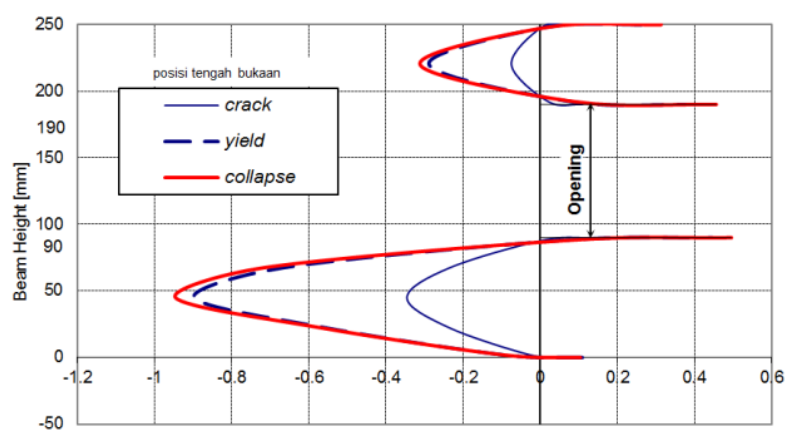

Shear Stress [MPa]

a. Middle chords

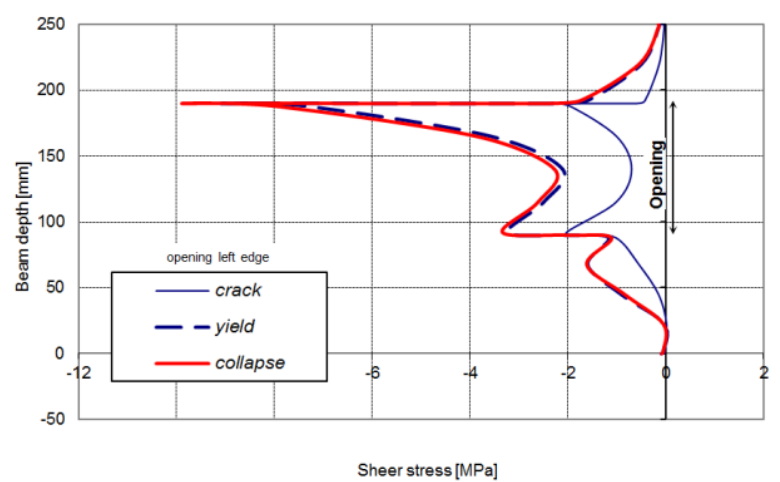

b. Left-opening edges

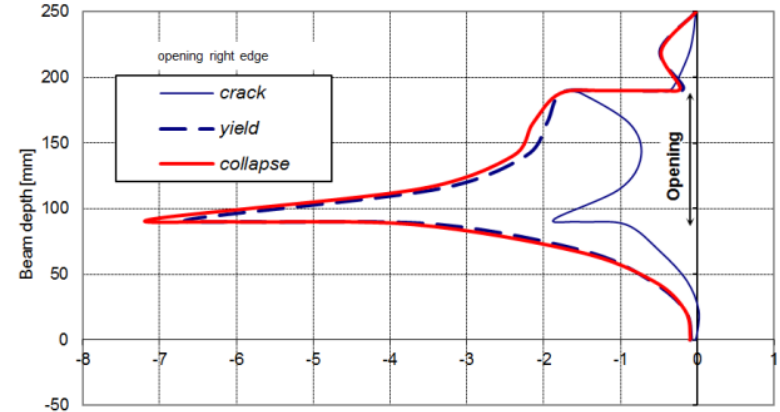

Shear stress $[\mathrm{MPa}]$

c. Right-opening edges

Fig. 3. Shear stress distribution fo BLT-2

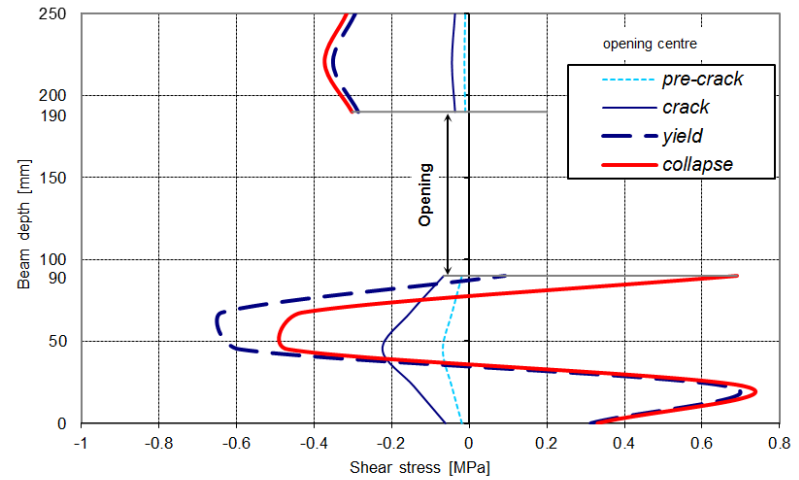

a. Middle chords

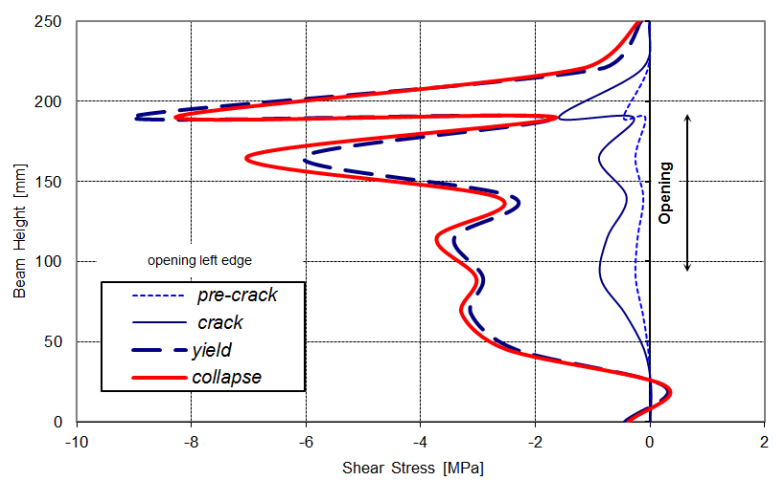

b. Left-opening edges

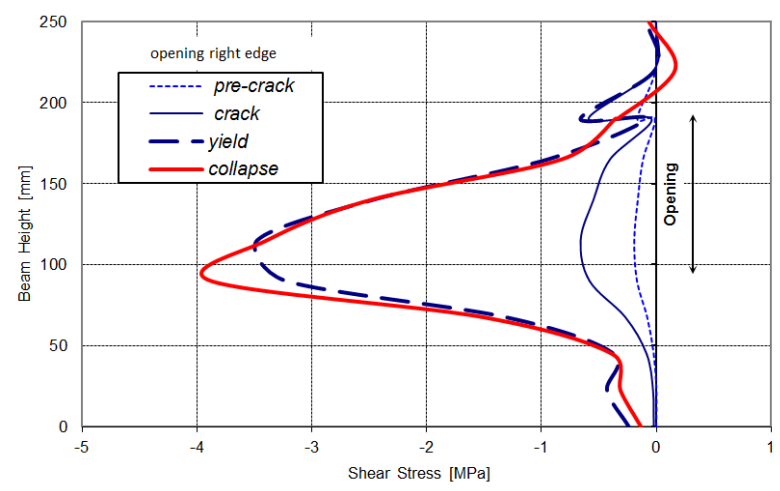

c. Right-opening edges

Fig. 4. Shear stress distribution fo BLT-3 


\section{Distribution of Shear Force between Top and Bottom Chords of Opening}

The area ratio $\left[A_{b} /\left(A_{t}+A_{b}\right)\right]$ named Area-1, the moment of inertia ratio $\left[\mathrm{I}_{b} /\left(\mathrm{I}_{t}+\mathrm{I}_{\mathrm{b}}\right)\right]$ named Inertia-1, the area root ratio $\left[\sqrt{ } A_{b} /\left(\sqrt{ } A_{t}+\sqrt{ } A_{b}\right)\right]$ named Area-2, the moment of inertia root ratio $\left[\sqrt{ } \mathrm{I}_{b} /\left(\sqrt{ } \mathrm{I}_{t}+\sqrt{\mathrm{I}_{b}}\right)\right]$ named Inertia-2 and the area-moment of inertia root ratio $\left[\sqrt{ } \mathrm{A}_{b} \mathrm{I}_{b} /\left(\sqrt{ } \mathrm{A}_{\mathrm{t}} \mathrm{I}_{t}+\sqrt{ } \mathrm{A}_{\mathrm{b}} \mathrm{I}_{\mathrm{b}}\right)\right]$ named Roof- 1 were compared to the results of the finite element analysis (Figure 5).

It was found that the results lie in between moment of inertia and the area - moment of inertia root ratio, which means that the shear force carried by each chord depends on both the area and moment of inertia of this chord. Applying statistical methods to the finite element results of the investigated beams, the shear force carried by each chord of opening was determined ([ $\sqrt{ } A_{b} I_{b} / 0.7$ $\left.\left(\sqrt{ } A_{t} I_{t}+\sqrt{ } A_{b} I_{b}\right)\right]$ named Roof-2). Figure 6 shows the shear force carried by the bottom chord of an opening in $\mathrm{T}$ section beams, using the area - moment of inertia root ratio given by:

$$
\frac{V_{b}}{V}=\frac{\left(\sqrt{A_{b} I_{b}}\right)}{0.7\left(\sqrt{A_{t} I_{t}}+\sqrt{A_{b} I_{b}}\right)}
$$

in which:

$\mathrm{V}_{\mathrm{b}} \quad$ = shear force carried by the bottom chord,

$\mathrm{V}=$ total shear force at the opening,

$A_{b}, A_{t}=$ cross sectional areas of bottom and top chords, respectively,

$\mathrm{I}_{\mathrm{b}}, \mathrm{I}_{\mathrm{t}}=$ moments of inertia of bottom and top chords, about their centroidal axes, respectively.

One can observe that the results based on the proposed root ratio given by Eq. (1) is the most suitable one to determine the proportion of shear carried by each chord. Therefore should be corrected by a factor of 0.7 for hybrid reinfoced concrete T-beams.

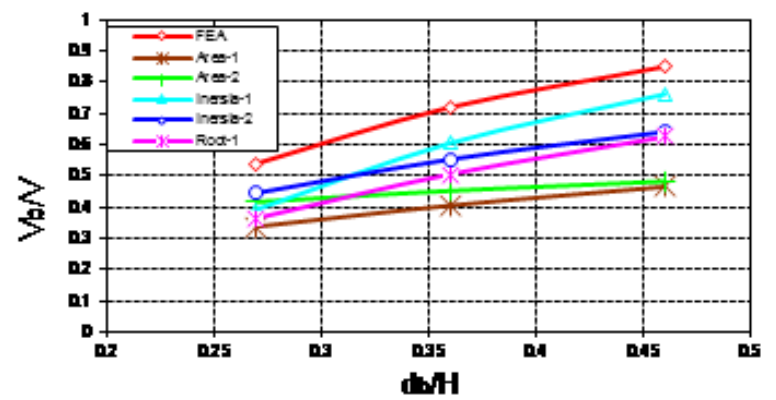

a. BLT-2

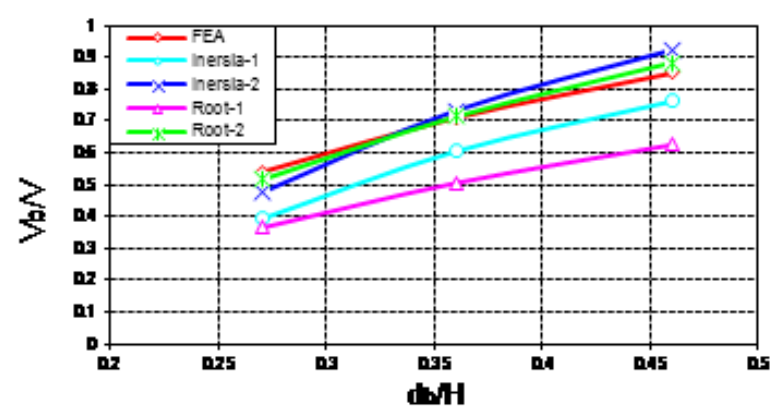

b. BLT-3

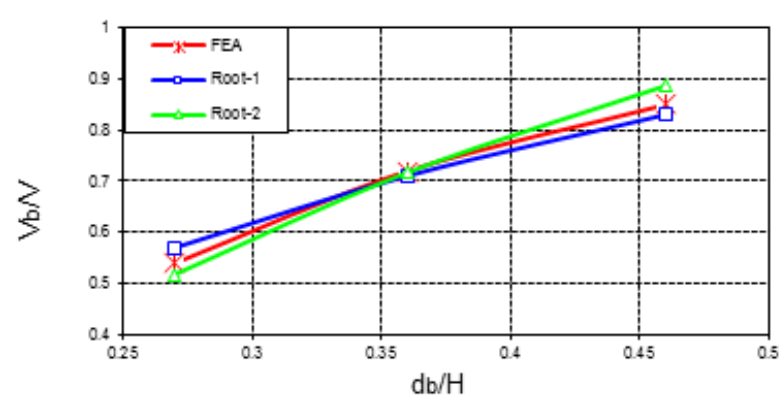

a. BLT-2

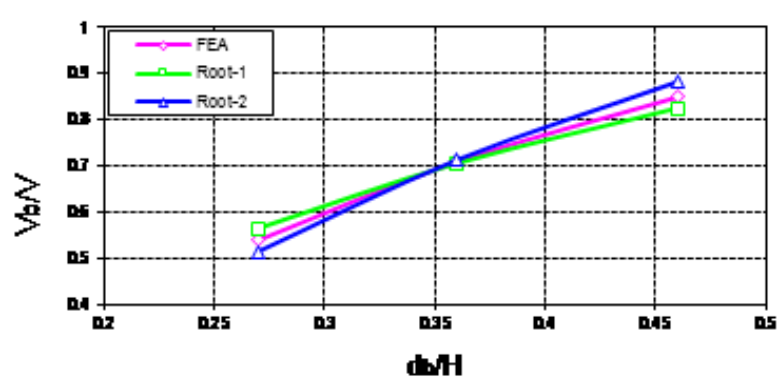

b. BLT-3

Fig. 6. $\mathrm{Vb} / \mathrm{V}$ vs $\mathrm{db} / \mathrm{H}$

\section{Conclusion}

The shear stress distribution at the middle of the top and bottom chords of the opening in pure bending region are zero. At the upper and lower corners of the opening occurs the maximum shear stresses. The maximum shear stress occur at the right lower corner chord at the high moment edge and at the left upper corner chord at the low moment edge in beams with openings at high shear and high flexural - shear region. The shear force at an opening in hybrid R/C T-beam is carried by the top and bottom chords of the opening according to the areamoment of inertia root ratio with correction factor 0.70 .

This research was partially supported by Paulus Christian University of Indonesia. This support is gratefully acknowledged by the author.

\section{References}

1. Fawzy, K., et al., Performance of RC Beams with Web Opening Subjected to Pure Torsion Strengthened with CFRP, International Journal of Engineering and Innovative Technology (IJEIT) Vol. 4, July 2014, pp. 197-204)

2. Ali, A.Y., and Zghair, M.G., Experimental Investigation and Nonlinear Analysis of Hybrid, AlQadisiyah Journal For Engineering Sciences, Vol. 8, No. 2, 2015, pp. 99-119

3. Al-Sheikh, S.A., Flexural Behavior Of Rc Beams With Opening, Concrete Research Letter Journal ISSRES, Vol. 5 (2) June 2014, pp. 812-824

4. Amiri, S., et al., A review of design specifications of opening in the web for simply supported RC beams,

Fig. 5. $\mathrm{V}_{\mathrm{b}} / \mathrm{V} \mathrm{vs}_{\mathrm{b}} / \mathrm{H}$ 
Journal of Civil Engineering and Construction Technology Vol. 2(4) April 2011, pp. 82-89

5. Hafiz, R.B., et al., Effects of Opening on the Behavior of Reinforced Concrete Beam, IOSR Journal of Mechanical and Civil Engineering (IOSR-JMCE) Vol. 11, Issue 2 Ver. VII (Mar- Apr. 2014), pp. 52-61

6. Vivek, R., and Madhavi, T.C., Behaviour Of Reinforced Concrete Beam With Web Openings, ARPN Journal of Engineering and Applied Sciences Vol. 11 no. 9 May 2016, pp. 5993-5995

7. Barney, G.B., Corley, W.G., Hanson, J.M., and Parmelee, R.A., Behavior and Design of Prestressed Concrete Beam with Large Web Openings, PCI Journal, Vol. 22, No.6, Nov.-Dec. 1997, pp. 3261

8. Dinakaran, V., and Sastry, M.K. (1984), Behaviour of post-tensioned prestressed concrete T-beams with large web openings, Indian Concrete J., Bombay, India, Vol. 58, No. 2, 1984, pp. 34-38

9. Hibbitt, H.D., Karlsson, B.I., Sorensen, E.P., ABAQUS Version 5.7, Finite Element Program, Hibbitt, Karlsson and Sorensen Inc., Providence, Rhode Islang 02906-4402, 1997

10. Chen, C.C., et al., Experimental Study Of Steel Reinforced Concrete Beams With Web Openings, The 14th World Conference on Earthquake Engineering October 2008

11. Long, X., and Lee, C.K., Modelling of Two Dimensional Reinforced Concrete Beam-Column Joints Subjected to Monotonic Loading, Journal of Advances in Structural Engineering September 2015, pp. 1461-1474

12. Sinaei, H., et al., Evaluation of reinforced concrete beam behaviour using finite element analysis by ABAQUS, Scientific Research and Essays Vol. 7(21) June 2012, pp. 2002-2009

13. Tanijaya, Jonie, Parametric Study of Web Opening Dimensions on Hybrid Reinforced Concrete TBeams, International Journal of Structural Analysis and Design, Vol. 1 : Issue 3, September 2014, ISSN : 2372-4102, SEEK Digital Library, pp. 60 - 64

14. Kennedy, J.B., and Abdalla, H.A., Static Response Of The Pre-Stressed Girder With Openings, J.Struct. Engrg., ASCE, Vol. 118, No. 2, 1992, pp. 488-504 